\title{
ON THE MODE OF FORMATION OF 1,6-DIHYDRO-NAD IN NADH PREPARATIONS
}

\author{
by \\ SVEN ERIK GODTFREDSEN and MARTIN OTTESEN \\ Department of Chemistry, Carlsberg Laboratory, \\ Gamle Carlsberg Vej 10, DK-2500 Copenhagen, Valby \\ and

\section{NIELS RASTRUP ANDERSEN}

LEO Pharmaceutical Products, Industriparken 55,

DK-2750 Copenhagen, Ballerup

Keywords: Lactate dehydrogenase inhibitor, NAD oxidoreductase, high pressure liquid chromatography, carbon-13 nuclear magnetic resonance, HPLC, ${ }^{13} \mathrm{C}$ NMR

The identity of the product obtained by sodium borohydride reduction of $\mathrm{NAD}^{+}$as 1,6-dihydro-NAD has been verified by ${ }^{13} \mathrm{C}$ NMR spectroscopy. The behaviour of this compound during chromatography on Sephadex G-15 has been found identical with that of the humidity induced inhibitor detected in NADH preparations and postulated to be identical with 1,6-dihydro-NAD. Evidence is presented that this inhibitor is responsible for the bulk of the inhibitory effect developed in moist NADH preparations and that it is generated through a bimolecular reaction between $\mathrm{NADH}$ and $\mathrm{NAD}^{+}$which in essence is a $\mathrm{NAD}^{+}$catalyzed double bond rearrangement of $\mathrm{NADH}$ effected by transfer of hydride anions from $\mathrm{NADH}$ to $\mathrm{NAD}^{+}$. One implication of these findings, that removal of $\mathrm{NAD}^{+}$from $\mathrm{NADH}$ preparations should convey increased stability to the reduced cofactor, has been verified. The structure of the lactate dehydrogenase inhibitors described in the literature is discussed.

Abbreviations: $\mathrm{NADH}=$ 1,4-dihydro-nicotinamide adenine dinucleotide, $\mathrm{LDH}=$ lactate dehydrogenase, $\mathrm{ADPR}=$ adenosine $5^{\circ}$-diphosphoribose, $\mathrm{NAD}^{+}=$nicotinamide adenine dinucleotide, 1,6-dihydro- $\mathrm{NAD}=$ 1,6-dihydronicotinamide adenine dinucleotide, TMS $=$ tetramethyl silane, compound $2=4$-phosphoryloxy-1,4-dihydro-nicotinamide adenine dinucleotide. 


\section{INTRODUCTION}

The numerous and important applications of NADH in clinical chemistry and the corresponding severe problems posed by the formation of potent enzyme inhibitors in NADH preparations have prompted several attemts to identify the inhibitors generated in NADH with the purpose of devising rational measures to prevent the formation of these substances and thus to increase the reliability of clinical analyses involving the coenzyme $(5,6,7,10,11,13,15,18$, 19). However, because of the many problems involved mainly in isolation of quantities of inhibitors sufficient for carrying out proper spectroscopic characterization, only few inhibitors in NADH preparations have actually been identified. One such inhibitor is ADPR [1] (Scheme 1). Another is compound [2] which was recently detected in small quantities by BiELLMANN et al. (2) in NADH preparations and prepared by these authors by addition of phosphate anion to $\mathrm{NAD}^{+}$. A third inhibitor formed in moist NADH has recently been assigned structure [3] on the basis of comparison with 1,6-dihydro-NAD prepared by sodium borohydride reduction of $\mathrm{NAD}^{+}$according to a modification of the Chaykin procedure (8). 1,6dihydro-NAD prepared by this method proved to be a potent, competitive inhibitor of lactate dehydrogenase and to exhibit UV spectroscopic properties very similar to those of NADH $(1,6-$ dihydro-NAD exhibits UV maxima at 260 and $343 \mathrm{~nm}$ and a ratio between the absorptions at these wavelengths of $\left.3.6\left(E_{260} / E_{343}=3.6^{8}\right)\right)$. A potent lactate dehydrogenase inhibitor possessing UV spectroscopic properties similar to those of

\section{Scheme 1}<smiles>[2H]C1(O)OC2COC3C(O)C(OC2C1O)OP(=O)(O)O[PH](O)(O)OCC1OC(n2cnc4c(N)ncnc42)C1C3O</smiles>

[1]

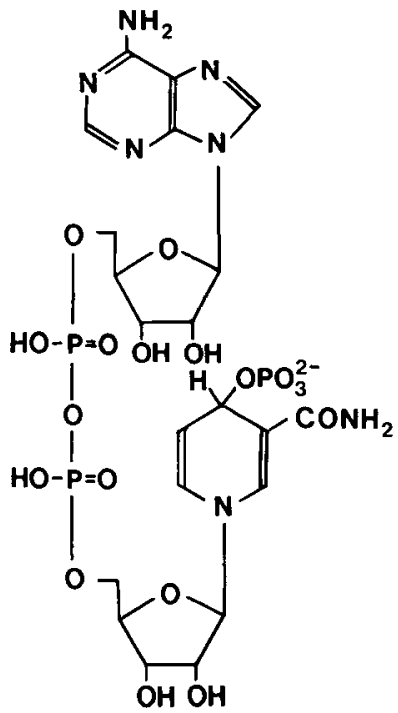

[2]

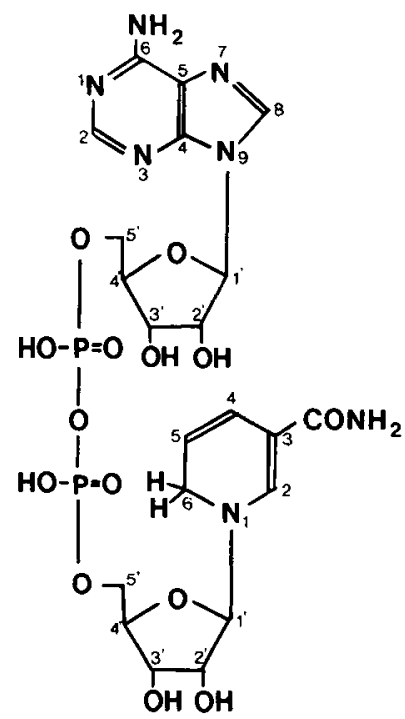

[3]
ADENOSINE 5:DIPHOSPHORIBOSE
4-PHOSPHORYLOXY-1,4DIHYDRO-NICOTINAMIDE ADENINE DINUCLEOTIDE

\section{1,6-DIHYDRO-NICOTINAMIDE ADENINE DINUCLEOTIDE}

\footnotetext{
$\S$ Due to the instability of 1,6-dihydro-NAD, the value given in ref. (8) for its $E_{260} / E_{343}$ ratio was slightly overestimated and should be corrected to 3.6. The higher value found for the $E_{260} / E_{343}$ ratio of the purified inhibitor isolated from moist NADH (8) compared to the ratio observed for pure 1,6-dihydro-NAD can presumably be explained by the low stability of this compound. For the same reason the $K_{i}$ given (8) for 1,6dihyro-NAD was slightly underestimated and should be corrected to $0.25 \mu \mathrm{M}$.
} 
1,6-dihydro-NAD was also detected by BiELLMANN et. al. in moist inhibitor enriched NADH (2). Contrary to the behaviour expected for 1,6dihydro-NAD, this inhibitor was found to chromatograph like a dimer of $\mathrm{NAD}^{+}$during gel filtration on Sephadex G-15 and it was therefore considered by BiellmanN et al. (2) to be a dimer. However, this substance had to be different from the 4,4'-dimer of $\mathrm{NAD}^{+}$since an authentic specimen of this material was found not to be an inhibitor of lactate dehydrogenase. Since it is known that $\mathrm{NAD}^{+}$dimers may be confused with NADH isomers (4) we have checked that the product obtained by sodium borohydride reduction of $\mathrm{NAD}^{+}$according to a modified Chaykin procedure (8) is actually 1,6-dihydroNAD. In addition, we have investigated further the formation of this substance in NADH preparations with the aim of understanding more fully the mechanism of inhibitor formation in NADH.

\section{MATERIALS AND METHODS}

NADH was a high purity commercial preparation manufactured from brewers yeast by the Carlsberg Breweries, Copenhagen, Denmark. Lactate dehydrogenase (LDH) was a gift from Dr. S. BAYNe and prepared from pig hearts. Tris-(hydroxymethyl)-methylamine (Tris) was from Sigma Company, U.S.A. 1,6-dihydroNAD was prepared according to a modification of the Chaykin procedure as described previously (8).

Inhibitor-enriched NADH was generated by dissolving NADH (disodium salt, $250 \mathrm{mg}$ ) in Tris buffer $(0.1 \mathrm{M}, \mathrm{pH} 8.8,250 \mu \mathrm{l})$ and storing the resulting solution at room temperature well protected from light. At intervals, aliquots $(5 \mu \mathrm{l})$ of the solution was transferred to water $(5 \mathrm{ml})$, analyzed by HPLC and diluted further with Tris buffer to adjust the absorbance of the solution at $340 \mathrm{~nm}$ to 1.0 corresponding to $160 \mu \mathrm{M}-\mathrm{NADH}$. The inhibitory effect of the solution was then measured after addition of sodium pyruvate and LDH (7). To determine $\mathrm{K}_{\mathrm{i}}$ an aliquot $(5 \mu \mathrm{l})$ of the NADH solution was diluted with water $(5 \mathrm{ml})$ after 312 hours, and the inhibitory effect of 100 and $200 \mu \mathrm{l}$ portions of this solution was measured using varying concentrations of $\mathrm{NADH}$ in the assay mixture. Fractionation by
HPLC of the products formed after 336 hours was performed using $200 \mu \mathrm{l}$ of a solution prepared by diluting $5 \mu$ of the NADH solution with water $(5 \mathrm{ml})$. Fractions of $0.5 \mathrm{ml}$ were collected and their inhibitory effect was measured after addition of LDH, sodium pyruvate and NADH. The results were compared with the inhibitory effect observed using the unfractionated solution.

High pressure liquid chromatography (HPLC) was carried out, essentially as described by MARGoLIs et al. (15) with a liquid chromatograph from Waters Associates equipped with a variable wavelength detector Model 450 and a $\mu$ Bondapak $\mathrm{C}_{18}$ column, also from Waters Associates. The elution solvent was $0.02 \mathrm{M}$ phosphate buffer ( $\mathrm{pH} 6)$ and the flow rate 1.8 $\mathrm{ml} / \mathrm{min}$. The recorder used was a Hewlett Packard integrator model 3380 A. Concentrations of NADH and 1,6-dihydro-NAD were calculated using extinction coefficients at $340 \mathrm{~nm}$ of 6.22 and $4.3 \mathrm{~cm}^{2} \cdot \mathrm{m}^{-6}$ respectively.

$\mathrm{LDH}$ reaction rates were determined as described by Gerhard et al. (7) using a LKB reaction rate analyzer Model 8600 .

${ }^{13} \mathrm{C}$ NMR spectra were recorded on a JEOL FX 100 spectrometer equipped with a $10 \mathrm{~mm}$ carbon probe using $16 \mathrm{~K}$ data point and JEOL DQ software. 5000-20.000 pulses were accumulated. The pulse width was $90^{\circ}$, the pulse repetition time $1.4 \mathrm{sec}$., and the sweep width $6024 \mathrm{~Hz}$. Chemical shifts in ppm downfield relative to tetramethyl silane (TMS) were calculated using dioxane as an internal reference set as $66.5 \mathrm{ppm}$ downfield from TMS. The solvent used was $D_{2} 0$, Uvasol from Merck Company. The probe temperature was $29^{\circ} \mathrm{C}$ and the concentration of 1,6-dihydro-NAD $40 \mathrm{mg} \cdot \mathrm{ml}^{-1}$.

Gel filtrations were carried out using a column of Sephadex G-15 $\left(35 \cdot 1.6 \mathrm{~cm}^{2}\right)$ equilibrated with Tris buffer ( $\mathrm{pH} 8.5,0.1 \mathrm{~m})$. Inhibitor enriched NADH prepared by incubating NADH $(50 \mathrm{mg}$ ) for 44 hours at room temperature in the dark with Tris buffer $(50 \mu 1,0.1 \mathrm{~m}, \mathrm{pH} 8.8)$ was diluted with water $(1 \mathrm{ml})$ and applied to the column. A flow rate of $75.6 \mathrm{ml} \cdot \mathrm{h}^{-1}$ was maintained and the absorption of the effluent was monitored at 260 and $340 \mathrm{~nm}$. Fractions were collected and analyzed by HPLC.

The influence of $\mathrm{NAD}^{+}$content on inhibitor formation in moist $\mathrm{NADH}$ was determined in 
the following way: $\mathrm{NAD}^{+}(180 \mathrm{mg})$ was dissolved in Tris buffer $(0.1 \mathrm{M}, \mathrm{pH} 7.0,2 \mathrm{ml})$ and $\mathrm{pH}$ of the resulting solution was adjusted to 8.8 by addition of sodium hydroxide $(2.5 \mathrm{M}$, approximately $100 \mu \mathrm{l})$. Samples of NADH (10 $\mathrm{mg}$ ) were moistened by addition of small portions of this solution followed by Tris buffer
(0.1 $\mathrm{M}, \mathrm{pH} 7.0)$ in order to adjust the total volume added to each sample to $10 \mu \mathrm{l}$. The samples were then left at room temperature protected from light for 24 hours and dissolved in water $(5 \mathrm{ml})$. Aliquots of these solutions were analyzed by HPLC recording the chromatogram at $340 \mathrm{~nm}$. The remaining solutions were
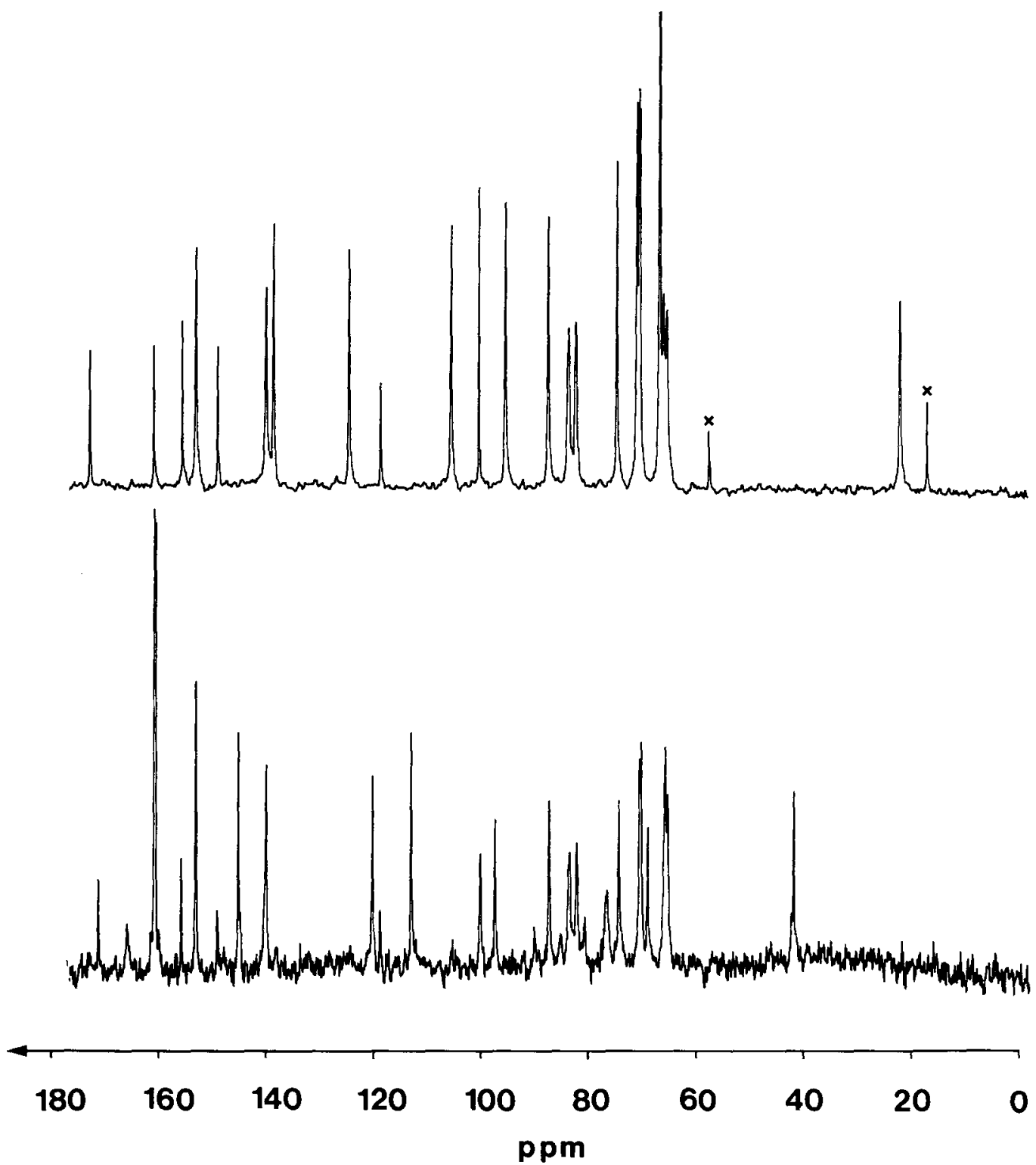

Figure 1. ${ }^{1} \mathrm{H}$ noise decoupled ${ }^{13} \mathrm{C}$ NMR spectra of NADH (upper trace) and 1,6-dihydro-NAD (lower trace). Chemical shifts are given in ppm downfield relative to TMS. The signals at $160 \mathrm{ppm}$ is due to ammonium bicarbonate. The signals labelled in the spectrum of NADH are due to an impurity of ethanol. See section 2 for details. 
Table I

${ }^{13} \mathrm{C}$ NMR resonances of 1,6-dihydro-NAD and NADH. Chemical shifts are given in ppm downfield relative to TMS and were calculated by using dioxane as an internal reference set as $66.5 \mathrm{ppm}$ downfield relative to TMS. $\mathbf{N}$ and $\mathbf{A}$ stand for the nicotinamide and adenosine moiety of the molecule. For numbering, cf. scheme 1.

\begin{tabular}{lccccccccccc}
\hline & $\mathrm{C}_{\mathrm{A}-2}$ & $\mathrm{C}_{\mathrm{A}-4}$ & $\mathrm{C}_{\mathrm{A}-5}$ & $\mathrm{C}_{\mathrm{A}-6}$ & $\mathrm{C}_{\mathrm{A}-8}$ & $\mathrm{C}_{\mathrm{N}-2}$ & $\mathrm{C}_{\mathrm{N}-3}$ & $\mathrm{C}_{\mathrm{N}-4}$ & $\mathrm{C}_{\mathrm{N}-5}$ & $\mathrm{C}_{\mathrm{N}-6}$ & $-\mathrm{CONH}_{2}$ \\
\hline $\begin{array}{l}\text { NADH } \\
\text { 1,6-dihydro- }\end{array}$ & 152.7 & 149.5 & 118.5 & 155.1 & 139.6 & 138.2 & 100.3 & 22.32 & 105.4 & 124.2 & 172.3 \\
NAD & 150.4 & 146.6 & 117.7 & 158.0 & 137.4 & 145.0 & 100.2 & 113.0 & 120.1 & 42.1 & 171.0 \\
\hline
\end{tabular}

\begin{tabular}{|c|c|c|c|c|c|c|c|c|c|c|}
\hline & $\mathrm{C}_{\mathrm{A}-1}$, & $\mathrm{C}_{\mathrm{A}-2}$ & $\mathrm{C}_{\mathrm{A}-3^{\prime}}$, & $\mathrm{C}_{\mathrm{A}-4^{\prime}}$ & $\mathrm{C}_{\mathrm{A}-5}$, & $\mathrm{C}_{\mathrm{N}-1}{ }$ & $\mathrm{C}_{\mathrm{N}-2}$ & $\mathrm{C}_{\mathrm{N}-3^{\prime}}$ & $\mathrm{C}_{\mathrm{N}-4^{\prime}}$ & $\mathrm{C}_{\mathrm{N}-5}$, \\
\hline $\begin{array}{l}\text { NADH } \\
\text { 1,6-dihydro- }\end{array}$ & 87.6 & 70.5 & 74.8 & 83.7 & 65.6 & 95.4 & 70.7 & 71.2 & 82.5 & 66.2 \\
\hline NAD & 87.2 & 69.4 & 74.6 & 83.6 & 65.6 & 97.5 & 70.8 & 71.2 & 82.2 & 66.0 \\
\hline
\end{tabular}

analyzed for their inhibitory effect after appropriate dilution. A similar experiment was carried out in which $\mathrm{pH}$ of the $\mathrm{NAD}^{+}$solution and the applied Tris buffer was adjusted to 9.8 .

The formation of inhibitors in NADH free of $\mathrm{NAD}^{+}$was investigated by exposing solid $\mathrm{NADH}$ to a solution $(10 \mu \mathrm{l})$ of sodium borohydride in Tris buffer $(0.5 \mathrm{mg}$ sodium borohydride $/ \mathrm{ml} 0.1 \mathrm{M}$ Tris, $\mathrm{pH} 8.8$ ). The resulting solution was allowed to stand for 15 minutes at room temperature. After dilution with water $(5 \mathrm{ml})$ the amount of 1.6-dihydroNAD formed was determined by HPLC and the inhibitory effect of the samples was measured by pyruvate reaction rates. Another sample of NADH was treated similarly but kept moistened with the sodium borohydride solution for 24 hours before being analyzed.

The influence of NADH on inhibitor formation in $\mathrm{NAD}^{+}$was monitored as follows: $\mathrm{NAD}^{+}$ $(1000 \mathrm{mg})$ was dissolved in Tris buffer $(1 \mathrm{ml}, 0.1$ $\mathrm{M}, \mathrm{pH}$ 8.8) and aqueous sodium hydroxide (approx. $5 \mathrm{~m}$ ) was added to adjust the volume of the solution to $1.5 \mathrm{ml}$ and the $\mathrm{pH}$ to 7.0 . Small portions $(10 \mu \mathrm{l})$ of this solution was then added to samples of $\mathrm{NADH}$, the resulting yellow solutions were left at room temperature protected against light for 20 hours, and finally diluted with water $(1 \mathrm{ml})$. The content of 1,6-dihydroNAD in the sample was then determined by HPLC recording the chromatogram at $340 \mathrm{~nm}$.

\section{RESULTS}

The ${ }^{13} \mathrm{C}$ NMR spectrum of 1,6-dihydro-NAD prepared according to a modification of the Chaykin procedure (8) is shown in Figure $I$ and summarized in Table I. For comparison the ${ }^{13} \mathrm{C}$ NMR spectrum of NADH is indicated. Based on the assignment of the ${ }^{13} \mathrm{C}$ resonances of NADH (3) it is seen that the signals corresponding to the adenine moiety and the two ribose units in NADH are present in the spectrum of 1,6dihydro-NAD at the expected positions with the exception that the signal due the anomeric carbon $\left(\mathrm{C}_{\mathrm{N}-1}\right.$ ) of the dihydropyridine carrying ribose is shifted slightly downfield in the spectrum of 1,6-dihydro-NAD. The most salient difference between the two spectra is the absence in the spectrum of 1,6-dihydro-NAD of the resonance at $22.3 \mathrm{ppm}$ attributable to $\mathrm{C}_{\mathrm{N}-4}$ in the spectrum of NADH and the appearance in the off-resonance spectrum of 1,6-dihydro-NAD of a triplet at the position expected $(12,16)$ for a methylene carbon flanked by a nitrogen atom and a carbon-carbon double bond (42.1 ppm). The signals due to $\mathrm{C}_{\mathrm{N}-2}$ and $\mathrm{C}_{\mathrm{N}-3}$ of 1,6-dihydroNAD are found at almost exactly the same positions as the corresponding signals in the spectrum of $\mathrm{NADH}$ while the remaining two signals, which must be assigned to $\mathrm{C}_{\mathrm{N}-4}$ and $\mathrm{C}_{\mathrm{N}-5}$ appear in the expected region of the spectrum $(12,16)$. The spectrum is thus in perfect accord with the structure of 1,6-dihydro-NAD and 


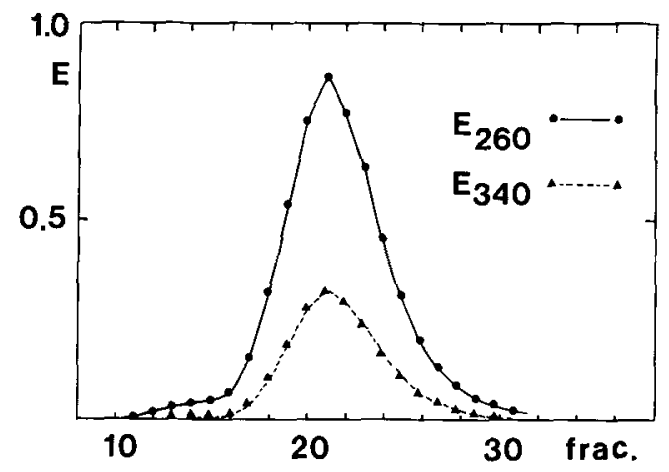

Figure 2. Chromatography of inhibitor enriched NADH on Sephadex G-15. Fraction 1-8 contained $2.52 \mathrm{ml}$, subsequent fractions $1.6 \mathrm{ml}$. See section 2 for details.

cannot be interpretated in terms of a dimer which, first of all, would not exhibit a triplet at $42.1 \mathrm{ppm}$ in the off-resonance spectrum, and, in general, presumably exhibit a much more complicated spectrum.

Of course, these findings do not exclude the possibility that the inhibitor detected in moist $\mathrm{NADH}$ and tentatively assigned the structure of 1,6-dihydro-NAD is actually a dimeric substance despite of the fact that it exhibits an UV spectrum similar to that of 1,6-dihydro-NAD and cochromatographs with this compound during DEAE as well as HPLC chromatography (8). A sample of inhibitor enriched NADH was therefore subjected to gel filtration on Sephadex G-15 and the chromatographic properties of the inhibitor and NADH was monitored by recording HPLC chromatograms of the various fractions collected. From the results which are

\section{Table II}

Gel filtration of inhibitor enriched NADH. Content of 1,6-dihydro-NAD in fractions collected during chromatography of inhibitor enriched NADH on Sephadex G-15, cf. Figure 2.

\begin{tabular}{cc}
\hline Fraction No. & 1,6-dihydro-NAD/NADH \\
\hline 18 & $2.3 \%$ \\
20 & $2.6 \%$ \\
25 & $3.3 \%$ \\
30 & $1.3 \%$ \\
\hline
\end{tabular}

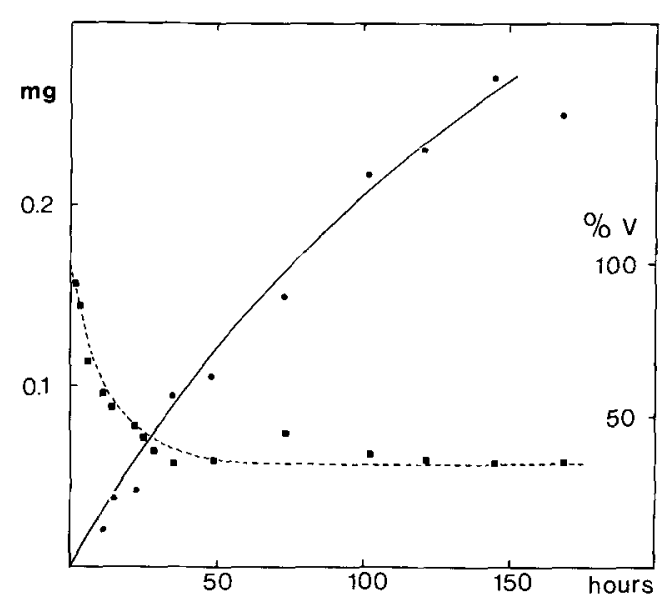

Figure 3. Generation of 1,6-dihydro-NAD in moist $\mathrm{NADH}$ at $\mathrm{pH}$ 8.8. The quantigy of 1,6-dihydro-NAD generated in moist NADH (-๑) is given in $\mathrm{mg}$ detected in a solution prepared by dissolving $5 \mathrm{mg}$ of the moist NADH in $5 \mathrm{ml}$ of water. Also given in the figure is the enzyme reaction rate observed when using the solution of the inhibitor enriched NADH in the applied enzymatic test after having adjusted the absorption of the solution at $340 \mathrm{~nm}$ to 1.0 corresponding to a concentration of NADH of approximately $160 \mu \mathrm{M}(\boldsymbol{\square}-\mathbf{D})$.

indicated in Table II and Figure 2 it is seen that the inhibitor and NADH cochromatograph on Sephadex G-15. The results are not in accord with a dimeric inhibitor but they do provide additional support for the hypothesis that the inhibitor formed in moist NADH at $\mathrm{pH} 8.8$ and which exhibits an absorption at $340 \mathrm{~nm}$ is identical with 1,6-dihydro-NAD.

The time course of the formation of 1,6dihydro-NAD in moist NADH at $\mathrm{pH} 8.8$ was studied utilizing the possibility of detecting the quantity of this inhibitor in NADH preparations by integration of the HPLC chromatograms recorded at $340 \mathrm{~nm}$. The results are indicated in Figure 3 together with the inhibition observed when using the inhibitor enriched NADH in the applied enzymatic test. It is seen that the amount of 1,6-dihydro-NAD generated under the applied conditions increased steadily during the experiment while the observed enzymatic reaction rates only decreased during the first part of the experiment and then levelled off. The $K_{i}$ calculated for 1,6-dirydro-NAD developed in the 


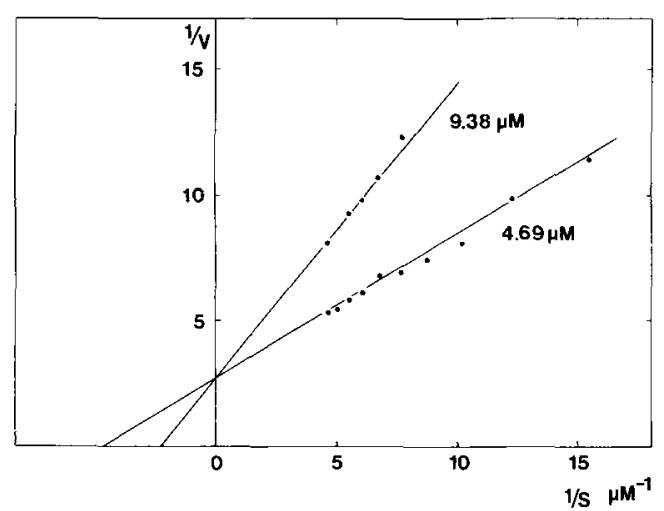

Figure 4. Double-recriprocal plots of relative reaction rates with pyruvate and $\mathrm{LDH}$ as function of NADH concentration with inhibitor enriched NADH added to the reaction mixture. The concentrations of 1,6dihydro-NAD in the reaction mixtures are indicated and were calculated on the basis of the HPLC chromatogram of the inhibitor enriched NADH. From the slopes a $K_{i}$ of $0.25 \mu \mathrm{M}$ was calculated for 1,6-dihydro-NAD.

moist sample using the results of the first part of the experiment was approximately $0.15 \mu \mathrm{M}$. During the last part of the experiment it was necessary to use a very dilute solution of the inhibitor enriched material and varying concentrations of NADH in order to obtain an accurate estimation of $\mathrm{K}_{\mathrm{i}}$. The value obtained on the basis of such experiments performed after 336 hours and using two fixed concentrations of inhibitor enriched NADH was $0.25 \mu \mathrm{M}$ (Figure 4).

Because of the reasonable agreement between the $\mathrm{K}_{\mathrm{i}}$ of separately prepared 1,6-dihydro-NAD and the $K_{i}$ calculated for the inhibitor formed in moist NADH it seems plausible that most of the inhibitory power developed in such samples can be attributed to 1,6-dihydro-NAD. In order to check this hypothesis an aliquot of a portion of NADH which had been exposed to moisture at pH 8.8 was separated into its components by semipreparative HPLC whereupon the inhibitory effect of all fractions collected was determined. From the results visualized in Figure 5, it is seen that, except for a slight inhibition observed in fractions presumably containing ADPR (retention time approx. $6 \mathrm{~min}$ ), significant inhibition was detected only in fractions containing 1,6-dihydro-NAD. Moreover, the

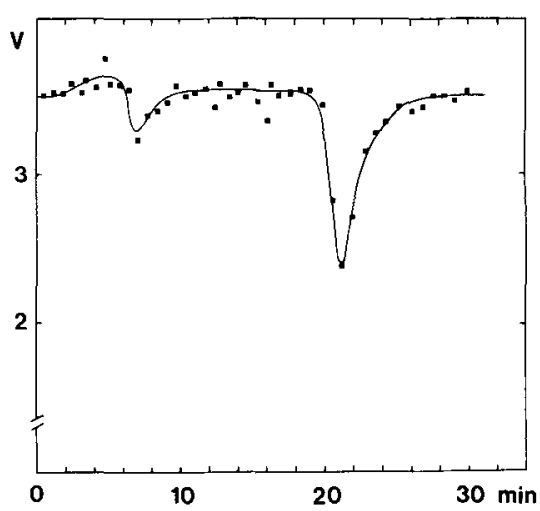

Figure 5. Relative reaction rates (V) of fractions obtained during semipreparative HPLC of inhibitor enriched NADH. The retention time of 1,6-dihydroNAD (21.6 $\mathrm{min}$ ) was obtained from the corresponding chromatogram recorded at $340 \mathrm{~nm}$.

sum of the inhibitions observed using these fractions accounted for the total inhibitory effect measured using the unfractionated material. This implies that no inhibitor was lost during the chromatography and thus renders it probable that 1,6-dihydro-NAD is responsible for the bulk of the inhibitory power of the moist sample. This is supported by the observation that $K_{i}$ for an authentic specimen of ADPR was found to be approximately $300 \mu \mathrm{M}$ in the applied system. A comparison of this value with the $K_{i}$ of $0.25 \mu \mathrm{M}$ of 1,6-dihydro-NAD makes it understandable that ADPR will only contribute little to the inhibitory power developed in moist NADH despite of the fact that appreciable quantities of this compound can be detected in moist NADH preparations.

The hypothesis has been advanced (8) that 1,6dihydro-NAD is generated in NADH preparations by a bimolecular reaction between NADH and the small quantities of $\mathrm{NAD}^{+}$which is usually present in samples of $\mathrm{NADH}$, the idea being that $\mathrm{NADH}$ may function as a hydride donor and transfer hydride anions to $\mathrm{NAD}^{+}$. Depending upon which site in $\mathrm{NAD}^{+}$accepts the hydride anions transferred from NADH the bimolecular reaction will lead to generation of either 1,2-, 1,4-, or 1,6-dihydro-NAD from $\mathrm{NAD}^{+}$under concomitant generation of $\mathrm{NAD}^{+}$ from the NADH participating in the reaction (Scheme 2). One major implication of this 
Scheme 2

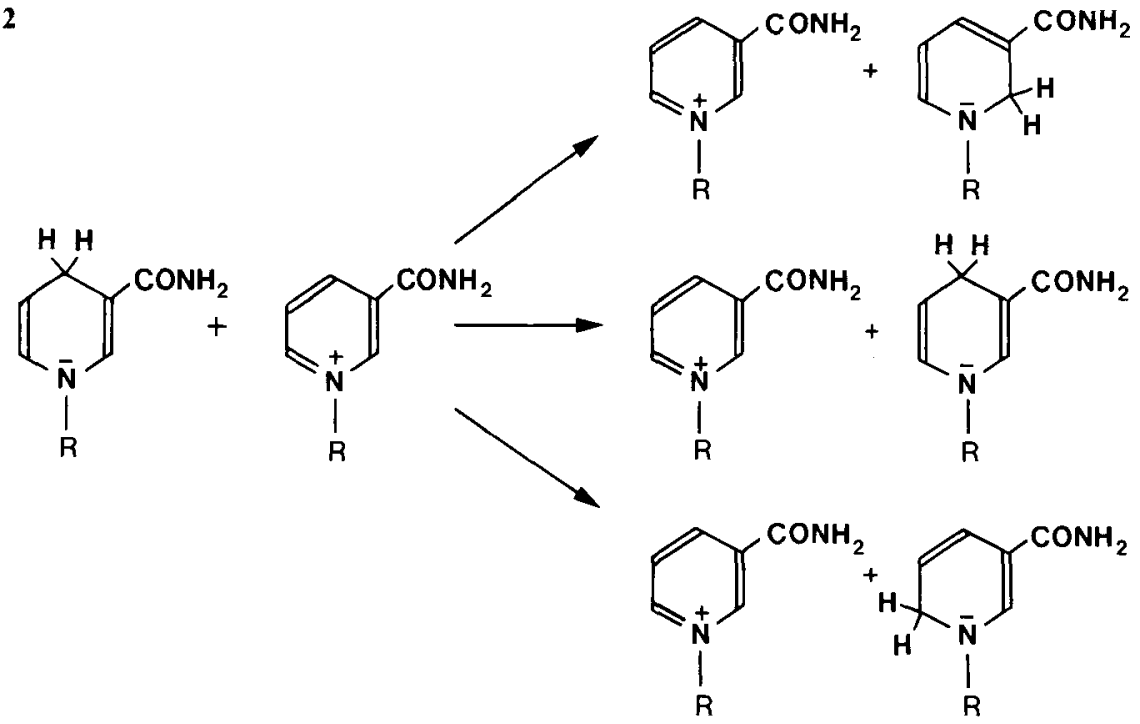

mechanism which in essence is a $\mathrm{NAD}^{+}$ catalyzed double bond isomerization of $\mathrm{NADH}$, is that the rate of formation of 1,6-dihydro-NAD in NADH preparations should be proportional to the amount of $\mathrm{NAD}^{+}$present as long as the quantity of $\mathrm{NAD}^{+}$is small compared to that of NADH. Conversely, the formation of the inhibitor in $\mathrm{NAD}^{+}$-preparations should be pro- portional to their content of NADH when this is present in only small amounts.

These predictions have been checked by measuring by HPLC $(340 \mathrm{~nm})$ the amount of 1,6-dihydro-NAD developed during 24 hours in $\mathrm{NADH}$ enriched with $\mathrm{NAD}^{+}$and in $\mathrm{NAD}^{+}$ enriched with NADH. The results which are shown in Table III and Figure 6 clearly indicate

Table III.

Formation of 1,6-dihydro-NAD in moist NAD ${ }^{+}$enriched NADH.

\begin{tabular}{ccccc}
\hline & $\begin{array}{c}\text { I,6-dihydro-NAD } 8 \\
\mathrm{mg}\end{array}$ & $\begin{array}{c}\text { measured } \\
\text { inhibition } \\
\%\end{array}$ & $\begin{array}{c}\text { calculated } \\
\text { inhibition } \\
\%\end{array}$ \\
\hline $\mathrm{pH} 7.0$ & & & \\
& $1.6 \%$ & 0.15 & 30 & 34 \\
& $4.0 \%$ & 0.33 & 43 & 49 \\
& $8.8 \%$ & 0.44 & 51 & 59 \\
& $15.6 \%$ & 0.62 & 57 & 65 \\
& $18.4 \%$ & 0.56 & 60 & 67 \\
& $25.6 \%$ & 0.56 & 62 & \\
$\mathrm{pH} 9.8$ & & & 51 \\
& & & - & 53 \\
& $3.9 \%$ & 0.32 & 57 & 58 \\
& $8.5 \%$ & 0.36 & 61 & 60 \\
& $13.2 \%$ & 0.45 & 64 & 68 \\
\hline
\end{tabular}

$\S$ In mg present in the solution prepared by dissolving the moist $\mathrm{NAD}^{+}$enriched $\mathrm{NADH}$ in $5 \mathrm{ml}$ of water. 


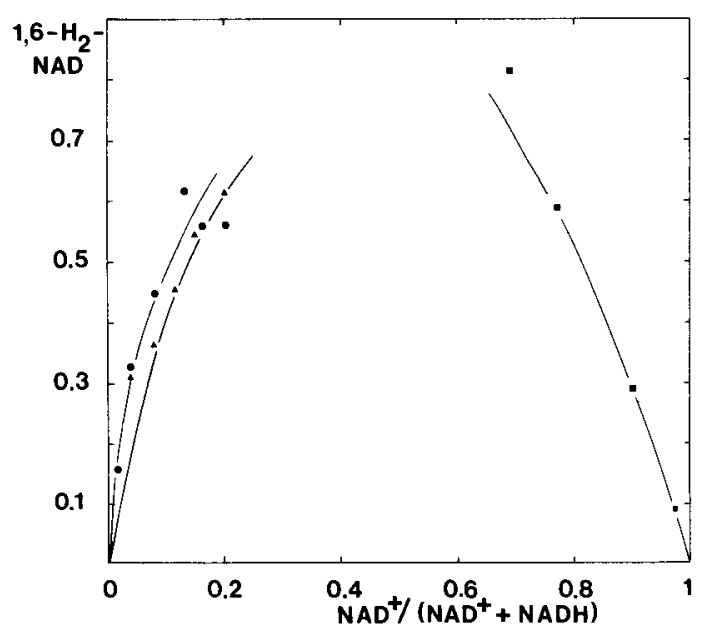

Figure 6. Generation of 1,6-dihydro-NAD in $\mathrm{NAD}^{+}$ enriched $\mathrm{NADH}$ and in NADH enriched $\mathrm{NAD}^{+}$at pH $7.0(-\bullet)$ and $\mathrm{pH} 9.8(\boldsymbol{\Delta}-\mathbf{\Delta})$. The amount of 1,6-dihydro-NAD generated is given in $\mathrm{mg}$ in the sample analyzed. The values given for 1,6-dihydro$\mathrm{NAD}$ generated in $\mathrm{NADH}$ enriched $\mathrm{NAD}^{+}$are multiplied with 1.5 corresponding to the higher dilution of the NADH enriched NAD ${ }^{+}$.

the expected relationships between inhibitor formation and $\mathrm{NAD}^{+}$content in $\mathrm{NADH}$ and between inhibitor formation in $\mathrm{NAD}^{+}$and its content of NADH. The results show only a minor influence of $\mathrm{pH}$ on the rate of inhibitor formation within the applied $\mathrm{pH}$ range. As indicated, the inhibitory effect observed using $\mathrm{NAD}^{+}$enriched NADH samples were found to agree well with the values predicted from the amount of 1,6-dihydro-NAD detected by HPLC (Table III).

One implication of these findings is that no or very little inhibitor formation should take place in NADH preparations completely free of $\mathrm{NAD}^{+}$or in other words that removal of $\mathrm{NAD}^{+}$ from NADH should convey increased stability to the NADH sample. This has been checked by
Table IV

Development of inhibitory power in $\mathrm{NAD}^{+}$free NADH.

$\%$ inhibition

NADH treated for 15 minutes with sodium borohydride in Tris

NADH treated for 24 hours under nitrogen with sodium borohydride in Tris

10

tracing inhibitor formation in a sample of NADH kept under nitrogen and moistened with a dilute solution of sodium borohydride which will reduce any $\mathrm{NAD}^{+}$present in the sample to NADH or its isomers without affecting 1,6dihydro-NAD $\$$. As is apparent from Table IV the borohydride reduction led, as expected, to the formation of some inhibitor. No further inhibitory power developed in the moist sample during the subsequent 24 hours. Actually, the inhibition as well as the content of 1,6-dihydro-NAD decreased slightly presumably reflecting the instability of the inhibitor.

\section{DISCUSSION}

The various lactate dehydrogenase inhibitors detected in NADH preparations can be divided into two main groups according to the characteristics published. The inhibitors described by Dalziel (5), Kaplan et al. (11), Wenz et al. (compound 8) (19) and Margolis et al. (15) constitute one group. These compounds exhibit a UV spectrum very similar to that of $\mathrm{NADH}$ and they cochromatograph with NADH during DEAE chromatography unless potassium bicarbonate is used to effect elution (19). The findings described in section 3 and the properties of 1,6-

\footnotetext{
$\S \S$ During preparation of 1,6-dihydro-NAD by sodium borohydride reduction of $\mathrm{NAD}^{+}$it was noted that one of the primarily formed isomers was resistant to further reduction while the other isomer was quantitatively reduced by the reducing agent. Based on analogy to the course of sodium borohydride reductions of simple model compounds (17) and the isolation and characterization of the relatively stable 1,6-dihydro-NAD from the reaction mixture it is likely that the secondary reaction taking place is a reduction of 1,2 -dihydro-NAD to $1,2,5$, 6-tetrahydro-NAD.
} 
dihydro-NAD (8) makes it likely that these inhibitors are identical with 1,6-dihydro-NAD. As far as the inhibitor described by WENZ (19) is concerned this structural assignment is supported by the observation made during our spectroscopic investigations of 1,6-dihydro-NAD that this compound, like compound 8 of WENZ, isomerized to NADH at $\mathrm{pH} 8$ and that both compounds hydrolyze rapidly to ADPR at low $\mathrm{pH}$ values.

Another group of inhibitors has been described by STRANDJORd and Clayson (18) and others $(6,9,10,13,14)$. They differ from the Dalziel type of inhibitors by exhibiting only a weak absorption at $340 \mathrm{~nm}$ and by being easily separable from NADH by chromatography on DEAE cellulose or Sephadex. From the results of GALATTI (6) it is well established that at least one inhibitor belonging to this group is formed not from NADH but $\mathrm{NAD}^{+}$and can be prepared by incubating $\mathrm{NAD}^{+}$with tri-potassium phosphate for a few days in a moist atmosphere. Similarly, BiellmanN recently prepared compound [2] from $\mathrm{NAD}^{+}$by incubation of this substance with dipotassium hydrogenphosphate in water at $\mathrm{pH} 11$ (2). These conversions emphasize the importance of both the $\mathrm{pH}$ of the reaction mixture and the nature of the inorganic salts present in relation to inhibitor formation and may, taken together with the findings described in the present paper, explain why inhibitors belonging to different groups are found by different authors in NADH preparations.

\section{ACKNOWLEDGEMENTS}

The authors are most grateful to dr. J. F. BIELLMANN et al. for providing a preprint of their article quoted as ref. 2 and to Mrs. HaNne Christiansen for her skilled technical assistance.

\section{REFERENCES}

1. Berry, A. J., J. A. Lott \& G. F. Grannis: NADH preparations as they affect the reliability of serum lactate dehydrogenase determinations. Clin. Chem. 19, 1255-1258 (1973)
2. Bifllmann, J.-F., C. Lapinte, E. Haid \& G. WeimanN: Structure of lactate dehydrogenase inhibitor formed from coenzyme. Biochemistry (in press)

3. Blumenstein, M. \& M. A. Raftery: Natural abundance ${ }^{13} \mathrm{C}$ nuclear magnetic resonance spectra of nicotinamide adenine dinucleotide and related nucleotides. Biochemistry 12, 35853590 (1973)

4. Burnett, R. \& A. L. Underwood: A dimer of diphosphopyridine nucleotide. Biochemistry 7 , 3328-3333 (1968)

5. Dalziel, K.: An inhibitor of liver alcohol dehydrogenase in preparations of reduced $\mathrm{di}$ phosphopyridine nucleotide. Nature 191, 10981099 (1961)

6. Galatti, H.: Beitrag zur Charakterisierung des Oxidoreductase-Inhibitors. J. Clin. Chem. Clin Biochem. 14, 15-22 (1976)

7. Gerhardt, W, B. Kofoed, L. Westlund \& B. Pavlu: Quality control of NADH. Supplement 139, J. Clin. Lag. Invest, Stockholm (1974)

8. Godtfredsen, S. E. \& M. Ottesen: 1,6-dihydroNAD as an humidity induced lactate dehydrogenase inhibitor in NADH preparations. Carlsberg Res. Commun. 43, 171-175 (1978)

9. Holman, M. J., J. E. Willis \& J. M. Siegel Formation and characteristics of a lactic dehydrogenase inhibitor in DPNH preparations. Clin. Chem. 12, 543 (1966)

10. Harkonen, M., V. Hanninen, O. Wahlroos \& H. ADLERCREUTZ: Studies on the purity and storage of NADH. Quality control in clinical chemistry, Walter de Gruyter (1975)

11. Kaplan, N. O., C. P. Fawcett \& M. M. CiotTi: Inhibition of dehydrogenase reactions by a substance formed from reduced diphosphopyridine nucleotide. Biochim. Biophys. Acta 54, 210-212 (1961)

12. Levy, G. C. \& G. L. Nelson: Carbon-1 3 nuclear magnetic resonance for organic chemists. Wiley Interscience (1972)

13. Loshon, C. A., R. B. McComb, L. W. Bond, G. N. Bowers, W. H. Coleman \& R. H. GWynN: Formation and properties of lactate dehydrogenase inhibitors in NADH. Clin. Chem. 23, 1576-1580 (1977)

14. МсСомв, R. B. \& R. J. Gay: A comparison of reduced-NAD preparations from four commercial sources. Clin. Chem. 14, 775 (1968)

15. Margolis, S. A., B. F. Howell \& R. Schaffer: Lactate dehydrogenase inhibitors in NADH preparations. Clin. Chem. 23, 1581-1584 (1977)

16. Pretsch, E., T. Clerc, J. Seibl \& W. Simon: Tabellen zur Strukturaufklarung Organischer 
Verbindungen mit Spectroskopischen Methoden. Springer Verlag (1976)

17. Shaw, E. N.: Quaternary pyridinium compounds. The chemistry of heterocyclic compounds. Interscience Publishers (1961)

18. Strandjord, P. E. \& K. J. Clayson: The control of inhibitory impurities in reduced nicotinamide adenine dinucleotide in lactate dehydrogenase assay. J. Lab. and Clin. Med. 67, 144-153 (1966)

19. Wenz, I., U. Loesche, U. Till, H. Petermann \& A. HORN: Purification and characterization of commercial NADH and accompanying dehydrogenase inhibitors. Jour. Chrom. 120, 187-196 (1976) 